\title{
Armadilhas da culpabilização materna
}

The Pitfalls of Motherhood Culpability

\author{
Alana Aragão Ávila' ${ }^{1}$ (iD) 0000-0002-1457-2718 \\ 'Universidade Federal de Santa Catarina, Programa de Pós-Graduação em \\ Antropologia Social, Florianópolis, SC, Brasil.88040-900-ppgas@contato.ufsc.br
}

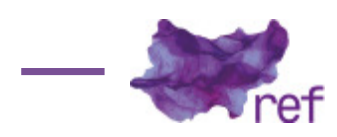

MERUANE, Lina.

Contra os filhos.

Trad. de Paloma Vidal. São Paulo: Todavia, 2018.

Abordar a maternidade e o instinto materno enquanto construções sociais permanece sendo tarefa árdua. Desde Simone de Beauvoir ([1949] 2016), passando por Elizabeth Badinter (1985) até Silvia Alexim Nunes (2000) e Lurdes Fidalgo (2003), a discussão sobre esses temas é recebida de forma controversa na arena quase sacralizada da construção da feminilidade pela via do papel materno. Propondo uma discussão atualizada não apenas sobre a maternidade em suas diversas formas e práticas, mas também sobre seus efeitos produtivos, Lina Meruane entrou para a miríade de autoras que desafiaram as convenções em torno da maternidade.

O mais recente livro de Lina Meruane a chegar no mercado brasileiro leva a provocação para além do título. Contra os filhos se propõe a ser um ensaio que discute o local privilegiado em que os filhos foram colocados na atualidade. Meruane revisita o "ideal do dever-ser-da-mulher" (Lina MERUANE, 2018, p. 17) e anuncia que esse imaginário está tomando novas formas, a saber, "sua encarnação contemporânea agita os pés entre fraldas e berra sem descanso junto a nós" (MERUANE, 2018, p. 17).

Lina Meruane é uma escritora chilena, doutora em literatura hispano-americana pela Universidade de Nova York e, atualmente, professora na mesma instituição. Suas produções mesclam romance e não ficção e já receberam reconhecimentos como o Prêmio Anna Seghers em 2011 , pela qualidade de seu trabalho. Originalmente lançado em 2014, Contra os Filhos foi traduzido por Paloma Vidal e lançado no Brasil em 2018 pela Editora Todavia.

Apesar de buscar incluir o papel dos pais (e aqui leia-se homens) no debate em torno da maternidade e de seus encargos, são as mães as personagens principais do texto de Meruane. É em um diálogo contínuo e vibrante com a leitora, em forma de diatribe, que Meruane percorre a história para demonstrar como as mulheres foram constantemente direcionadas para o exercício da maternidade, de acordo com o necessário e recomendado a determinada época. Fosse entre guerras, gerando filhos para suprir o déficit populacional pelas morte de soldados ou como cuidadora da casa e dos filhos para que o marido fosse um expoente do capital no mundo do trabalho pago, a autora demonstra como as mulheres historicamente sofreram as pressões para se portarem de acordo com seus papéis de gênero, sendo o principal a maternidade.

A narrativa que Meruane lança mão para demonstrar o seu ponto de vista é prioritariamente a da história que permeia a Europa e os EUA. São nesses polos que busca grande parte de suas interlocutoras para dar base à sua premissa: nunca os filhos estiveram em um local tão privilegiado na vida cotidiana como agora e, mais ainda, as mulheres estão cada vez mais retornando às 
tarefas domésticas e a uma maternidade total. É através, principalmente, das figuras da "mãeecológica" (MERUANE, 2018, p. 123) e da "supermãe" (MERUANE, 2018, p. 124) que a autora tenta demonstrar como as crescentes recomendações para a maternidade tem ecos no confinamento da mulher ao lar. Problematizando o papel da mulher em práticas relacionadas à maternidade, tais como a amamentação prolongada em livre demanda, a utilização de fraldas de pano, a preparação da alimentação dos filhos mais próxima ao natural, o parto sem analgesia ou intervenções médicas etc., que Meruane embasa seus argumentos para lançar o alarme de que aparentemente a luta das antecessoras feministas pela independência feminina foi por água abaixo.

As práticas elencadas por Meruane se ligam especialmente à figura da 'mãe-ecológica' e utiliza, para tanto, o trabalho da filósofa francesa Elisabeth Badinter para corroborar sua perspectiva. Badinter lançou o livro O Conflito: a mulher e a mãe (2011) abordando a discussão em torno do papel social da mulher como mãe e das demandas atualizadas referentes à maternidade com viés naturalista. É a partir dessa obra de Badinter que Meruane conduz várias de suas discussões em torno da exaustiva demanda direcionada às mães em torno dos filhos.

O trabalho de Meruane se insere no contexto de uma antiga discussão dentro do feminismo: a extensa responsabilização das mulheres pela criação dos filhos. Essa discussão tem ganhado novos contornos, impulsionados pela influência da ecologia nos processos da maternidade. E Meruane não apenas sabe disso como utiliza as demandas da maternidade de inspiração ecológica para provar que novamente são as mulheres que estão com a maior carga de trabalho na criação dos filhos (MERUANE, 2018, p. 106-110). Em uma discussão que recupera o clássico embate entre natureza e cultura, tão querido e controverso à antropologia, Meruane demonstra como estrategicamente a mulher foi colocada como próxima à natureza para justificar seu papel social de mãe. O instinto materno, a propensão ao cuidado, tudo é colocado sob o guarda-chuva da natureza e faz lembrar do clássico de Sherry Ortner, "Está a mulher para a natureza assim como o homem para a cultura?" (1979), no qual são levantadas hipóteses dos porquês da insistência social de aproximar a mulher da natureza e o homem da cultura e racionalidade. Fabíola Rohden (1996), ao explorar o que ela chama de ecofeminismo ou feminismo da diferença, afirma que "Essa nova perspectiva trazia propostas como a valorização da mulher como salvadora ecológica já que ela sempre teria estado mais próxima da natureza e mais distante dos processos de destruição ligados ao mundo público a sociedade industrial" (ROHDEN, 1996, p. 99).

Outro elemento essencial para pensar Contra os Filhos é como a autora utiliza a metáfora de um anjo, inspirado em um antigo poema de Coventry Patmore (MERUANE, 2018, p. 46), que fica insistentemente falando aos ouvidos das mulheres para que elas se sintam impelidas a tornaremse mães. Não só mães como devem ser boas mães, correspondendo aos preceitos do momento. A figura do anjo aparece também para assombrar as mulheres que escolhem não ser mães. Para elas, são dedicadas várias páginas buscando problematizar o porquê da ojeriza social à ideia de mulheres sem filhos, também sobre como os filhos e a escrita são praticamente incompatíveis para uma mulher. São do campo da literatura vários exemplos de Meruane para fundamentar sua crítica: Jane Austen, Virginia Woolf e Emily Dickinson aparecem como exemplos de abandono do papel social materno. Por outro lado, Meruane também traz o exemplo de Charlotte Perkins Gilman e Anne Sexton como exemplos de escritoras mães abaladas por depressões pós-parto.

O livro de Meruane é um longo protesto contra o "império dos filhos" (MERUANE, 2018, p. 149) às custas da subordinação materna, todavia existem críticas a serem feitas. Por mais que a autora convoque inúmeras outras escritoras e teóricas - infelizmente sem referências precisas - para corroborar com a ideia de que a sociedade impõe para as mulheres a reprodução e a exaustiva responsabilização sobre os filhos, o livro ainda dá a entender que os tais filhos tiranos da atualidade são resultado da educação que as mães têm ofertado, das renúncias que elas têm feito para atender a todas as necessidades da criança. Por mais que façam isso, de acordo com Meruane - porque existe uma conjuntura que diz que essa é a forma correta de exercer a maternidade - é ainda o efeito do fazer delas que cria esses filhos e que resultou no ensaio produzido pela autora. A escritora comenta que a opressão tem cúmplices para se perpetuar entre as próprias mulheres. De alguma forma, acaba soando como se não houvesse alternativa, além da culpa, para aquelas que já se tornaram ou almejam se tornar mães, ou, até mesmo, aquelas que venham a ser mesmo desviantes de seus desejos.

As formas de maternidade que Meruane aborda em seu texto são em sua maioria referenciadas pelas classes média e alta, deixando uma grande gama de mulheres e suas maternidades fora desse diálogo. Cabe então pensar onde, no cenário descrito pela autora, se inserem as maternidades dissidentes daquela mulher branca e cálida retratada em inúmeros quadros de pintores europeus como representação da maternidade. Como afirma Judith Butler (2015), seguindo a lógica do pensamento foucaultiano, "a produção discursiva do corpo materno como pré-discursivo é uma tática de autoampliação e ocultação das relações de poder específicas pelas quais o tropo do corpo materno é produzido" (BUTLER, 2015, p. 162). Nesse sentido, acredito 
ser necessário pensar tanto no corpo da mulher como destinado à procriação e à maternidade como também sobre quais corpos estão sendo representados nas discussões em torno desta maternidade problematizada. O que essas representações abarcam? O que (ou quem) fica de fora desse diálogo?

Apesar das críticas, há de se reconhecer o quão pedagógico é o texto de Meruane. Com uma linguagem simples, e fugindo de academicismos, ela constrói seu argumento para fundamentar sua crítica demonstrando como ao longo da história hegemônica a reprodução foi utilizada como mecanismo de controle das mulheres e seus corpos. Contra os filhos consegue chegar, por sua forma e conteúdo, às mulheres, mães ou não, feministas ou não, que estão perpetuamente dentro das discussões relacionadas à maternidade. Afinal, não há lugar fora da discussão da maternidade quando se nasce fêmea na cultura ocidental.

Problematizar a maternidade, em suas diversas formas, e os elementos que a contornam é possibilitar outros caminhos para além do destino social da mulher em nossa sociedade. É a possibilidade de aliviar um pouco do peso moral sobre a mulher que enfrenta o desafio materno em toda a sua amplitude. Todos os personagens evocados no texto de Meruane são provocações necessárias para chamar a atenção para o que autora aponta como um alerta: "a cada êxito feminista se seguiu um retrocesso, a cada golpe feminino um contragolpe social destinado a tomar os impulsos centrífugos da liberação" (MERUANE, 2018, p. 17). Em um momento global em que as discussões sobre gênero, sexualidade e parentalidade estão cada vez mais inflamadas, o alerta é extremamente necessário.

\section{Referências}

BADINTER, Elizabeth. O Conflito: a mulher e a mãe. Trad. de Vera Lúcia dos Reis. Rio de Janeiro: Editora Record, 2011.

BADINTER, Elizabeth. Um amor conquistado: o mito do amor materno. Trad. de Waltensir Dutra. Rio de Janeiro: Nova Fronteira, 1985.

BEAUVOIR, Simone de. O segundo sexo: fatos e mitos. 3. ed. Trad. de Sérgio Milliet. Rio de Janeiro: Nova Fronteira, [1949] 2016.

BUTLER, Judith. Problemas de gênero: feminismo e subversão da identidade. 8. ed. Trad. de Renato Aguiar. Rio de Janeiro: Civilização Brasileira, 2015.

FIDALGO, Lurdes. (Re)construir a maternidade numa perspectiva discursiva. Lisboa: Instituto Piaget, 2003.

MERUANE, Lina. Contra os filhos. Trad. de Paloma Vidal. São Paulo: Todavia, 2018.

NUNES, Silvia Alexim. O corpo do diabo entre a cruz e a caldeirinha: Um estudo sobre a mulher, o masoquismo e a feminilidade. Rio de Janeiro: Civilização Brasileira, 2000.

ORTNER, Sherry. "Está a mulher para a natureza assim como o homem para a cultura?". In: ROSALDO, Michelle Z.; LAMPHERE, Louise (Orgs.). Mulher, Cultura e Sociedade. Trad. de Cila Ankier e Rachel Gorenstein. Rio de Janeiro: Paz e Terra, 1979, p. 95-120.

ROHDEN, Fabíola. "Feminismo do Sagrado: uma reencenação romântica da diferença". Revista Estudos Feministas, Florianópolis, v. 4, n. 1, p. 96-117, 1996.

Alana Aragão Ávila (alanaavila01@yahoo.com.br) graduou-se em Psicologia pela Universidade Federal do Ceará (2015), no campus de Sobral, é mestranda em Antropologia Social pelo PPGAS/UFSC e integrante do TRANSES - Núcleo de Antropologia do Contemporâneo. Vem direcionando seus estudos para as áreas de políticas públicas, saúde, gênero, sexualidade e maternidade. 
COMO CITAR ESSE ARTIGO DE ACORDO COM AS NORMAS DA REVISTA

ÁVILA, Alana Aragão. "Armadilhas da culpabilização materna". Revista Estudos Feministas, Florianópolis, v. 28, n. 2, e65236, 2019.

\section{CONTRIBUIÇÃO DE AUTORIA}

Não se aplica.

\section{FINANCIAMENTO}

O presente trabalho foi realizado com apoio da Coordenação de Aperfeiçoamento de Pessoal de Nível Superior - Brasil (CAPES) - Código de Financiamento 001.

\section{CONSENTIMENTO DE USO DE IMAGEM}

Não se aplica.

\section{APROVAÇÃO DE COMITÊ DE ÉTICA EM PESQUISA}

Não se aplica.

\section{CONFLITO DE INTERESSES}

Não se aplica.

LICENÇA DE USO

Este artigo está licenciado sob a Licença Creative Commons CC-BY International. Com essa licença você pode compartilhar, adaptar, criar para qualquer fim, desde que atribua a autoria da obra.

\section{HISTÓRICO}

Recebido em 17/05/2019

Revisões requeridas em 16/10/2019

Aprovado em 13/01/2020 